\title{
Migración y Pediatría en Chile
}

\section{Migration and Pediatrics in Chile}

\author{
Colomba Norero V.a
}

aMiembro de Número, Academia Chilena de Medicina, Instituto de Chile

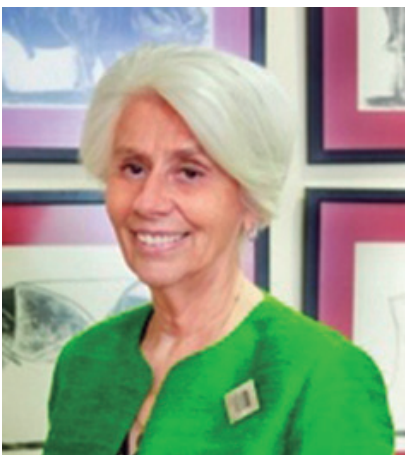

Hasta el año 2009 Chile recibía una cantidad considerada pequeña de inmigrantes, especialmente de Perú, Argentina y Bolivia los que llegaron a conformar el $1.2 \%$ de la población. A partir de esa fecha, desde el año 2013 en adelante el aumento ha sido creciente, llegando a estimarse el 2017 en 5.5\%/18 millones de habitantes.

Tan o más importante que estas cifras es la modificación del origen de los migrantes. Ya no son nuestros vecinos, culturalmente semejantes, con el mismo idioma y un pasado compartido; ahora predominan los migrantes de Haití, Venezuela, Colombia y República Dominicana los que en su mayoría migran de sus países por condiciones económicas y/o políticas, por falta de libertad y de proyecciones.

Chile los atrajo porque aquí había oportunidades de trabajo y por contar con estándares de desarrollo sustentable superiores a los de su país de origen.

Una gran dificultad para haitianos y dominicanos es el idioma, pero para todos lo son las diferentes costumbres en alimentación, conceptos de salud y enfermedad, y manera de relacionarse, que son muy distintas a la de los chilenos.

Habitualmente migran hombres sanos. Están dispuestos a trabajar y salir adelante. Sin embargo cuando viajan grupos familiares son las mujeres y los niños los que están en posición vulnerable de salud. Entonces surge el problema en Chile en cómo otorgar la ayuda que necesitan estas personas cumpliendo con las premisas de los derechos humanos.

Según la encuesta CASEN 2015, 26.6\% los niños migrantes de 0 a 14 años no tenían previsión de salud contrastado con $1.6 \%$ de los chilenos de igual edad que carecía de ella, diferencia que probablemente se ha incrementado, considerando que el 2017 el 7,8\% de los nacimientos fue de hijos de extranjeros. Felizmente en Chile el parto es atendido profesionalmente, lo que significa protección tanto para la madre como para el hijo, incluso a las madres migrantes con VIH.

Entonces para cumplir con nuestra obligación médica ¿qué debemos hacer los pediatras?

Antes que nada ser empáticos.

Entender que los migrantes son personas que han abandonado una cultura y deben asimilar otra y que están en una etapa inicial de adquisición especialmente en cuanto a educación sanitaria. Hay que infundirles confianza en el sistema y crear conciencia en el equipo de salud, a los pequeños pacientes chilenos y a sus madres con que comparten una sala de espera, que cada gesto amable hacia los migrantes hace mucho más que otras acciones para hacer su vida más esperanzadora y facilitar la convivencia.

En cuanto a la práctica profesional no se trata de conocer enfermedades tropicales, porque las posibilidades de adquirirlas son escasas. Pero sí debemos estar atentos a las patologías habituales de los niños en con- 
diciones de hacinamiento, como enfermedades respiratorias, diarrea, maltrato, y de pobreza, como desnutrición y enfriamiento.

Se debe conocer el esquema de vacunaciones de los países de origen, su grado de cumplimiento y la confianza que nos merezcan sus condiciones de realización para así complementar o realizar el esquema vigente en Chile evitando así la reaparición de enfermedades infectocontagiosas.

Asimismo se debe conocer el estado de salud de los padres, especialmente TBC y VIH, y derivar a padres y niños para su detección y tratamiento.

Es importante intentar efectuar seguimiento de los hijos de extranjeros nacidos en Chile (¡nuestros compatriotas!) para revisar los porcentajes de mortalidad neonatal al año de vida, así como los porcentajes de desnutrición comparados con hijos de chilenos de igual fecha de nacimiento.

Por su parte es posible que los adolescentes migrantes adquieran las patologías propias de nuestra sociedad de consumo, como son las alarmantes cifras de obesidad, tabaquismo, alcoholismo, drogadicción, y embarazos adolescentes en nuestro país.

Es así que la tarea de los pediatras es inmensa, porque implica luchar en dos flancos distintos pero así como en la década de los sesenta nos demostramos capaces de liberarnos de la desnutrición, de mejorar de manera dramática nuestras cifras de mortalidad infantil y neonatal, ahora debemos combatir extremos opuestos de patología como son la desnutrición y la obesidad infantil; validarnos como interlocutores en grupos humanos con otras culturas y de ningún modo bajar nuestros estándares de salud.

Abordar el problema de la migración descontrolada requiere contar con una política adecuada para el tema que tome en cuenta la limitada capacidad económica del país y un apoyo inteligente del Estado para poder realizar acciones que aseguren la protección de los derechos humanos tanto para nuestros compatriotas como para aquellos que han ingresado al país con intención de establecerse y para los hijos de padres migrantes que son ciudadanos chilenos.

Una buena señal ha sido la exigencia de visas en los respectivos consulados y la regularización de la situación de los migrantes en Chile. Asimismo, dentro de las políticas públicas que se están desarrollando al respecto, sería deseable que se estableciera un examen de salud, especialmente en relación a TBC y VIH, para quienes pretenden permanecer en el país, pero no como una manera de discriminación, sino muy por el contrario, para tratarlos de manera adecuada, eficiente y responsable.

\section{Conflicto de intereses}

La autora declara no tener conflicto de intereses. 